\title{
USE OF NEAR-INFRARED DETECTOR TO SENSE RF ANTENNA HEATING
}

\author{
by \\ R.A. LEGG, R.L. LEE, and W.F. BAITY†
}

This is a preprint of a paper to be presented at the 18th IEEE/NPSS Symposium on Fusion Engineering, October 25-29, 1999, Albuquerque, New Mexico, and to be published in the Proceedings.

tOak Ridge National Laboratory

Work supported by

the U.S. Department of Energy

under Contracts DE-AC03-99ER54463, and DE-AC05-960R22464

GA PROJECT 30033

NOVEMBER 1999 


\section{DISCLAIMER}

This report was prepared as an account of work sponsored by an agency of the United States Government. Neither the United States Government nor any agency thereof, nor any of their employees, make any warranty, express or implied, or assumes any legal liability or responsibility for the accuracy, completeness, or usefulness of any information, apparatus, product, or process disclosed, or represents that its use would not infringe privately owned rights. Reference herein to any specific commercial product, process, or service by trade name, trademark, manufacturer, or otherwise does not necessarily constitute or imply its endorsement, recommendation, or favoring by the United States Government or any agency thereof. The views and opinions of authors expressed herein do not necessarily state or reflect those of the United States Government or any agency thereof. 


\section{DISCLAIMER}

Portions of this document may be illegible in electronic image products. Images are produced from the best available original document. 


\title{
Use of Near-Infrared Detector to Sense RF Antenna Heating*
}

\author{
R.A. Legg, ${ }^{1}$ R.L. Lee, ${ }^{1}$ and W.F. Baity ${ }^{2}$ \\ ${ }^{1}$ General Atomics, P.O. Box 85608, San Diego, California 92186-5608 \\ ${ }^{2}$ Oak Ridge National Laboratory, Oak Ridge, Tennessee
}

\begin{abstract}
The three antennas used for ion cyclotron heating (ICH) experiments on DIII-D have experienced localized heating of the Faraday shield rods during plasma operations which has resulted in some melting. This melting is of great concern not only because of the damage it does to the rf system's ability to deliver rf to the plasma, but because of its potential to contaminate the plasma during a shot and cast the experimental results from the shot into question.

A real-time sensor to detect the temperature of the antennae during plasma operations is described. The sensor uses an avalanche photo diode (APD) with sensitivity from 0.4 to $1.0 \mu \mathrm{m}$ to monitor the temperature of the antennae. Calculations for the detector sensitivity based on Planck's law are compared with experimental results and detector data taken during plasma operations are presented.
\end{abstract}

\section{INTRODUCTION}

The use of radio frequency energy in heating and shaping plasmas has increased greatly in the last 15 years. This increase has lead to the installation of many new antennas designed to launch if energy into a plasma vessel. Erosion and localized melting of the antenna can occur when the plasma impinges on it. For DIII-D, this erosion shows up on the exposed Inconel parts of the $30-10 \mathrm{MHz}$ ion cyclotron heating antenna. The erosion is characterized by localized areas of melting $30-120 \mathrm{~mm}$ across on the $0.7 \mathrm{~m}$ square antenna. The melting occurs on a very short time scale and coupled with its local nature has lead to an assumption that the melting is a surface phenomenon. To determine when this erosion occurs, a new type of diagnostic was needed.

\section{DESCRIBE THE PROBLEM}

The location of the diagnostic had several constraints; if it was installed in the antennae structure, it had to be vacuum compatible and had to respond on time scales of a few milliseconds. If the diagnostic sat in the vessel, outside the antenna, it had to be vacuum and plasma compatible and had to be immune to the strong magnetic fields and eddy currents flowing in internal metal structures. These turned out to be impractical. This left the possibility of mounting the diagnostic outside the vessel, looking back through a diagnostic port at the antennae. This greatly simplifies the diagnostic by removing the vacuum requirements, but forces the diagnostic to be optical in nature.
Once a location for the diagnostic was settled on, the other constraints on the diagnostic were identified. First, discriminate between the small areas of $>800^{\circ} \mathrm{C}$ temperature and the much larger antenna which could be up to $400^{\circ} \mathrm{C}$ without concern. Second, look through a plasma which radiates at all hydrogen lines and has a few carbon lines thrown in for good measure. Third, operate consistently in a high radiation and magnetic field. Finally, meet the DIII-D requirement that $30 \mathrm{kV}$ electrical isolation be maintained between the DIII-D pit area and the outside world. Cost, schedule and ease of operation were also considerations.

To optically discriminate between a $0.5 \mathrm{~m}^{2}$ antenna at $400^{\circ} \mathrm{C}$ and $0.001 \mathrm{~m}^{2}$ area of melting at $800^{\circ} \mathrm{C}$ while peering through a hot plasma, several operating spectra were considered for the detector. Conventional heat detectors us longer wavelengths, $5-150 \mu \mathrm{m}$. At these wavelengths the plasma radiates less and the emission curve vs temperature for the antenna is close to linear. Unfortunately, because of the enhancement needed to compensate for the discrepancy in area between the antenna and the area at high temperature, a linear response is not desirable. The vacuum viewport at these longer wavelengths also becomes an issue since ordinary quartz or sapphire cutoff transmission at shorter wavelengths. Ultimately, long wavelength detectors were rejected.

To identify a better spectra, Planck's law for blackbody radiation was plugged into a spreadsheet with temperature and wavelength the free variables. The output power versus Wavelength has a characteristic shape, like a cresting wave, Fig. 1, which shifts to shorter wavelengths as the temperature is increased.

This shape causes the output power of a frequency just at the lower edge of the curve to increase exponentially with temperature as the crest of the curve moves across it much faster than the simple $\mathrm{T}^{4}$ relationship for total radiated power. By choosing the detector spectra to be just below the lower edge of this blackbody curve, the enhancement in detector response necessary to overcome the 500:1 ratio of antenna area to area of erosion with only a doubling of temperature is achieved. This bottom edge occurs between 1 and $2 \mu \mathrm{m}$ and that causes a problem. The transmission of ordinary glass cuts off around $1.2 \mu \mathrm{m}$. To use a spectra starting closer to $2 \mu \mathrm{m}$ requires special vacuum port materials. A more serious issue is the Paschen series for hydrogen between 1 and $2 \mu \mathrm{m}$. This series of hydrogen lines might give the detector a false indication during a particularly hot or dense plasma shot - the shots where the detector is most needed. To get away from

\footnotetext{
${ }^{*}$ Work supported by U.S. Department of Energy under Contracts DE-AC03-99ER54463 and DE-AC05-96OR22464.
} 


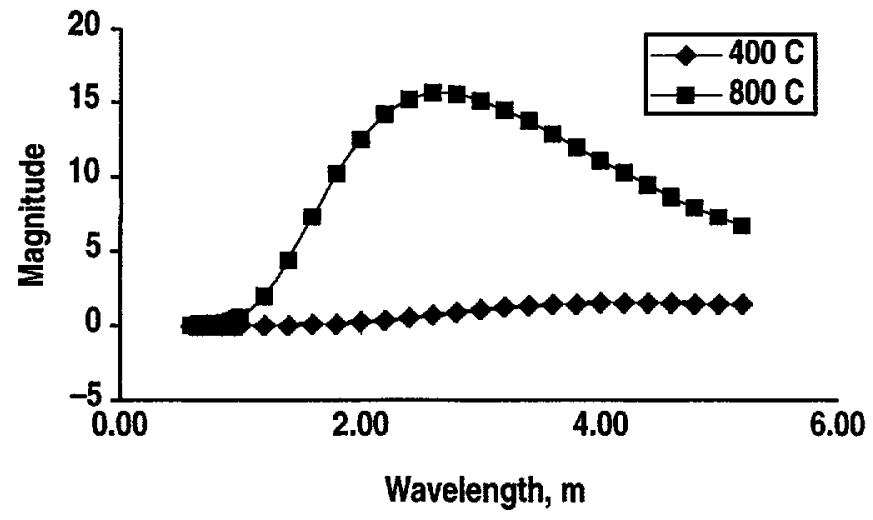

Fig. 1. Magnitude of blackbody radiation versus wavelength.

this series of lines, the detector spectra moved down below $1 \mu \mathrm{m}$. The lower end of the spectra is established by the very strong $\beta$ hydrogen line at $656 \mathrm{~nm}$. This leaves a relatively narrow operating spectra between 700 and $1000 \mathrm{~nm}$. In this range there are still a few faint hydrogen lines which were hoped to not interfere with the detector. If these hydrogen lines did blind the detector during the shot, the detector would still record the antenna radiation after the plasma dissipated but before the antenna could cool down, indicating a shot with possible erosion.

The relative intensity of the integrated spectra between 700 and $1000 \mathrm{~nm}$ versus temperature is shown in Fig. 2. Note the strong enhancement with temperature.

The next step was to select a detector for the spectra of interest. The detector needed to have a large output signal and it had to be compatible with the DIII-D radiation and magnetic environment. The ultimate goal for the detector was to give the operations staff an "erosion/no erosion" signal in real-time for each shot fired. A few discussions with other individuals using detectors on the vessel in the near infrared, suggested that a simple avalanche photodiode could be used in this application, and had already been used on the lithium pellet detector.

The detector is a Hammatsu C5460-01 and has a published spectral response from 0.4 to $1.0 \mu \mathrm{m}$ which peaks at $0.8 \mu \mathrm{m}$. To eliminate the hydrogen line at $656 \mathrm{~nm}$, a $720 \mathrm{~nm}$ high pass filter was installed in front of the detector. The normal detector cutoff was left to deal with the Paschen series of hydrogen lines above $1 \mu \mathrm{m}$. Finally, a lens system was installed to image the $0.7 \mathrm{~m}$ square antenna $2 \mathrm{~m}$ away onto the $3 \mathrm{~mm}$ diameter detector. Standard mount quartz lenses were used to reduce radiation darkening and all lenses were chosen as large as possible to improve the signal gathering of the detector.

The entire diagnostic was assembled and bench tested using a black body source. The source is a thermostatically controlled oven with a single $25 \mathrm{~mm}$ orifice. The detector was set up $2 \mathrm{~m}$ away from and on the center line with the orifice for the first test. The data, normalized for peak and offset, along with the theoretical prediction, are shown in Fig. 3. The data match the prediction very closely except for a scaling

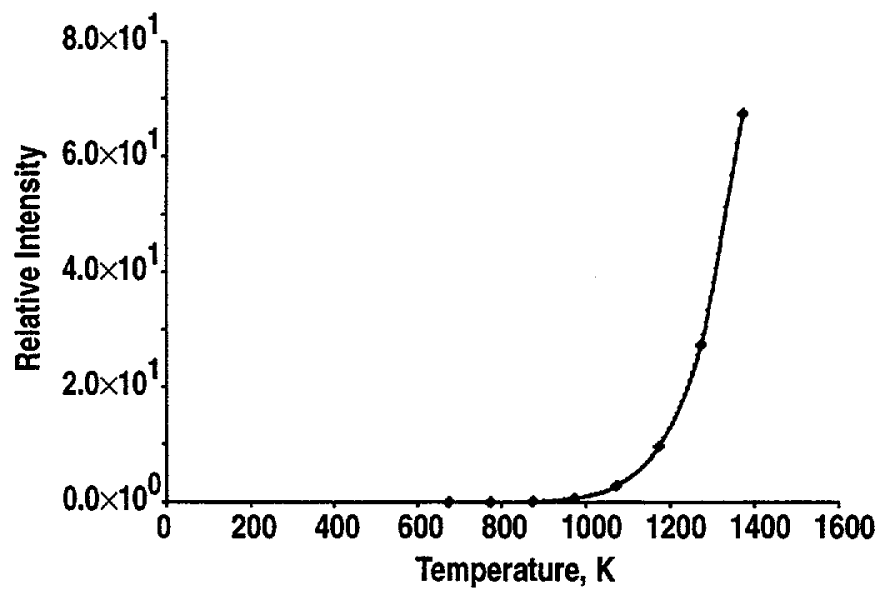

Fig. 2. Integrated blackbody spectra from 0.6 to $1.0 \mu \mathrm{m}$ as a function of temperature.

term which may be due to a low efficiency in the detector or poor transmission through the filter or lenses. The test was rerun with the detector off-centerline by $0.25 \mathrm{~m}$ to verify that this scaling term remained constant over the detector's field of view with similar results. As a last step the gain of the detector was set such that $800^{\circ} \mathrm{C}$ would give a $3 \mathrm{~V}$ output - enough to trip a TTL input if everything worked.

\section{RESULTS}

The detector was installed directly on a 1.75 in. window at the $105^{\circ} \mathrm{R}-1$ port using a polycarbonate lens holder. It looked across the toroid at the ICH antenna at $0^{\circ}$, approximately $2 \mathrm{~m}$ away. The first shots were taken with plasma, but with the detector mounted on a platform $2 \mathrm{~m}$ away from the vessel aimed away from the vessel. This was to get a baseline on the electrical noise in the area adjacent to the vessel. The signal from the detector looks good, but shows a lot of $120 \mathrm{~Hz}$, see Fig. 4. The labels on the figures are "TCHOPYROM" for ICH 0 degree antenna pyrometer, "IP" for plasma current, "BEAMS" for sum of neutral beam currents, and "PRAD_DIVL" for integrated plasma emission.

Shot 100,000 revealed the problem with the system. The detector sees the plasma with ELMs showing up unmistakably

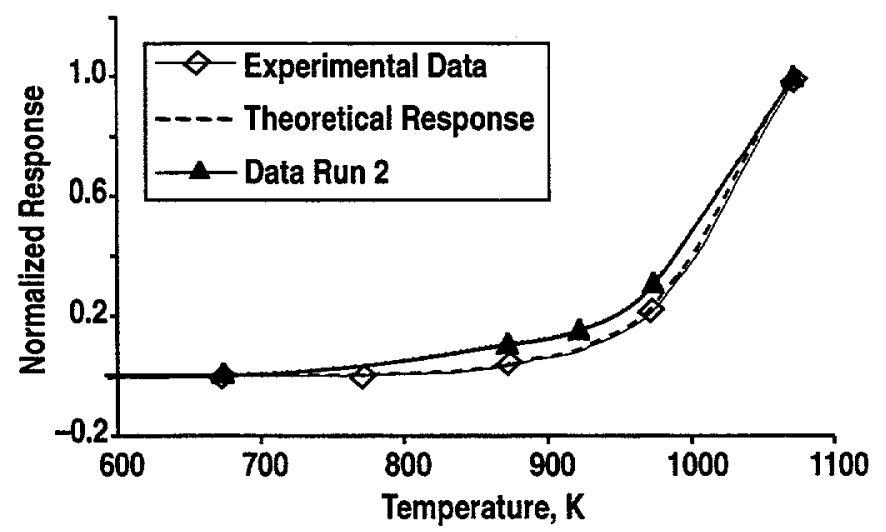

Fig. 3. Normalized results for blackbody response. 


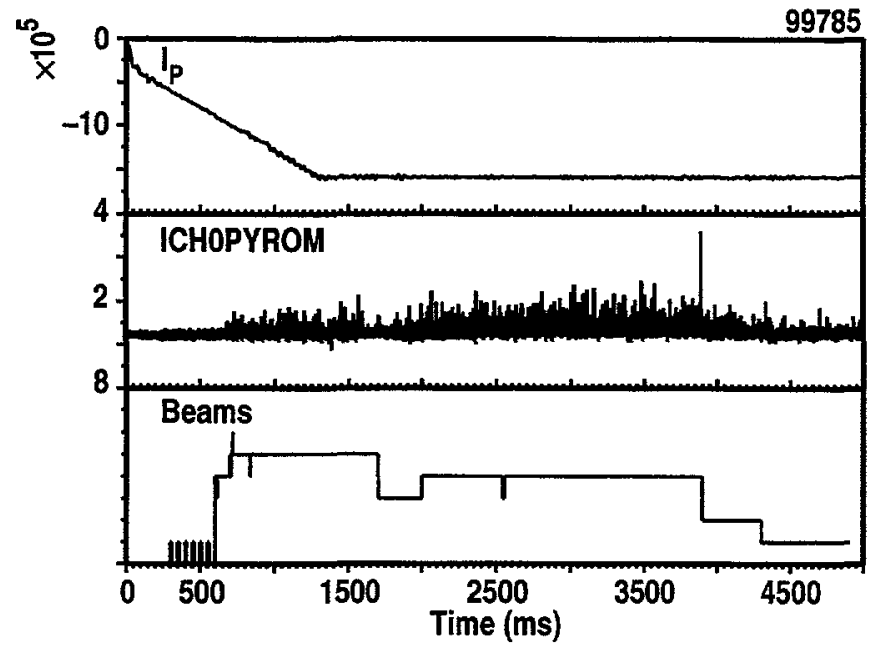

Fig. 4. Plasma shot with detector looking away from vessel.

in the output trace, is shown in Fig. 5. Shot 100,000 also shows that after a plasma disruption the detector saturates and then puts out no signal for 100 's of milliseconds.

This meant that not only was the detector unable to detect erosion during a plasma shot, it could not check the antenna temperature after a plasma disruption. During extreme conditions it failed. The detector could, however, detect an absence of heating on plasma shots with emission low enough to stay below the $3 \mathrm{~V}$ threshold. It could verify that the detected radiation dropped below the $3 \mathrm{~V}$ threshold after "hot" plasma shots which did not end in plasma disruption, Fig. 6, but any plasma shot which ended in a disruption was a question mark. That question mark and the systems' inability to see through the plasma notwithstanding, no detector value above $3 \mathrm{~V}$ was observed except during a plasma shot during the run period from June 18 until July 10, 1999. After the run period, the vessel was opened and no erosion was observed on the antenna.

To make the detector a useful tool and fulfill its promise as an operations diagnostic, several changes must be made. The detector must be made less sensitive to plasma disruption and to the plasma emission radiation. The most direct means of reducing the effect of a plasma disruption on an instrument is to move it further from the vessel. This also reduces radiation damage to the solid state detector and false counts caused by X-rays. To do this, a $2 \mathrm{~m}$ light guide with a $3 \mathrm{~mm}$ diameter matched to the detector has been ordered. This will allow the detector and its electronics to be moved outside the vessel coil packs and out of a direct line of sight with the port. It will greatly reduce the Eddy currents induced in the metal portions of the detector. It also will reduce the amount of light transmitted to the detector by $20 \%-30 \%$, but this can be compensated for by the gain in the detector. To reduce the detector's sensitivity to plasma emission, a second filter to strongly suppress the Paschen hydrogen lines above $957 \mathrm{~nm}$ will be implemented.

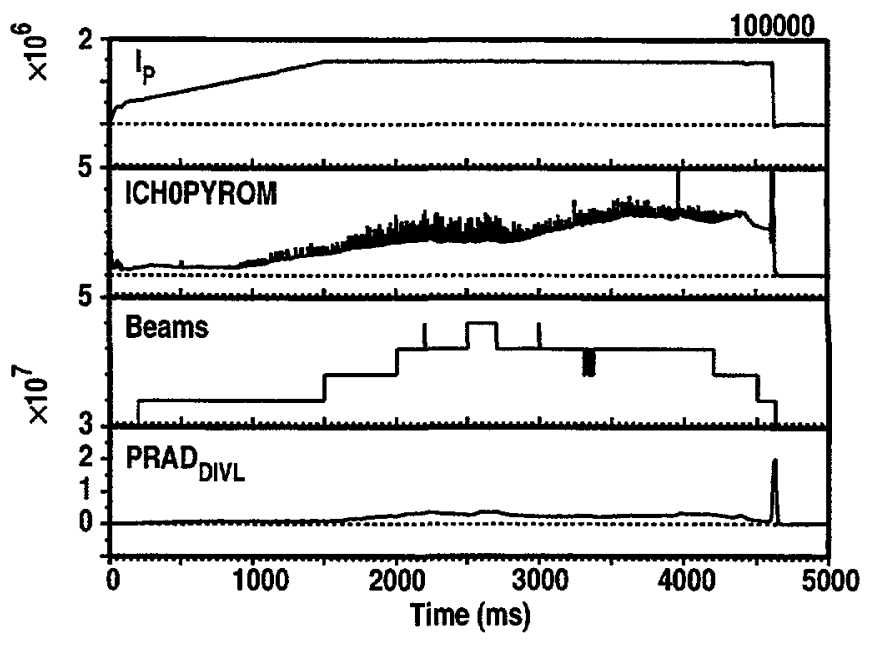

Fig. 5. Plasma shot with detector looking through plasma.

A more drastic approach to improving the signal to noise from the plasma emission is to move the operating spectrum of the diagnostic to a wavelength closer to the crest of the blackbody curve at $800^{\circ} \mathrm{C}$. This improves the peak signal strength from the antenna by more than an order of magnitude over the spectra just below $1 \mu \mathrm{m}$, allowing the sensitivity of the detector to be lowered along with the relative intensity of the plasma emission lines. Using the data from this run to estimate the strength of the integrated probabilities in the 700 to $1000 \mathrm{~nm}$ range and the published relative probabilites [1] of hydrogen emission lines, a guess at the relative strength of the integrated power spectra for hydrogen over any specified bandwidth versus the blackbody spectra can be achieved. The integrated transition probability from 700 to $1000 \mathrm{~nm}$ is six times greater than the probability from 1150 to $1800 \mathrm{~nm}$ (the next large hydrogen emission window). The blackbody emission from the antennas at $1073 \mathrm{~K}$ is more than 50 times greater at $2 \mu \mathrm{m}$ than at $1 \mu \mathrm{m}$. This would combine to improve the $\mathrm{S} / \mathrm{N}$ of the detector by more than two orders of magnitude.

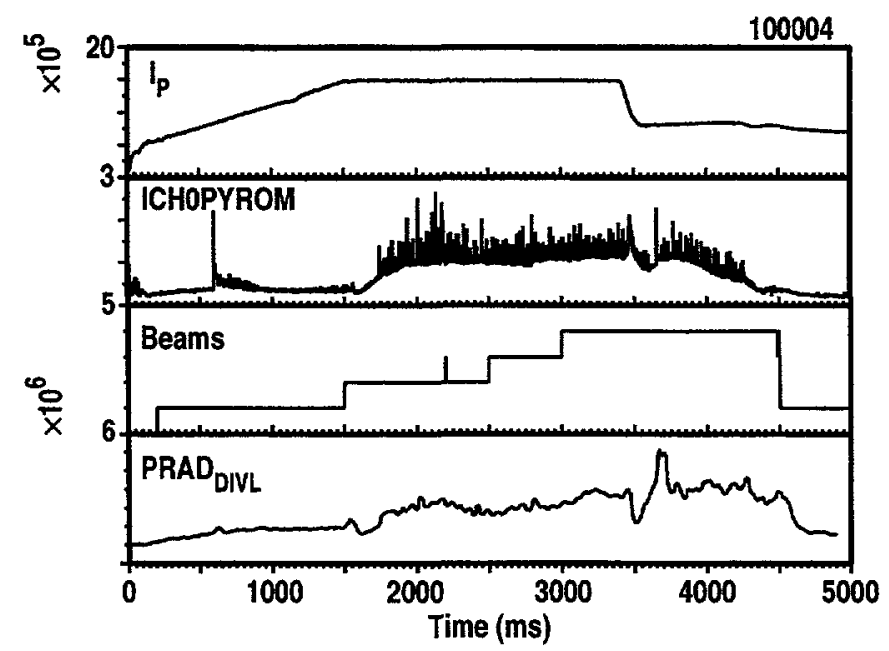

Fig. 6. Plasma shot without plasma disruption. 
Since the plasma emission intensities seen during this experimental series were on the same order as the results expected from the hot spot on the antenna, this improvement could dramatically effect the operation of the diagnostic.

\section{CONCLUSIONS}

An optical instrument for detecting an over temperature condition on rf antennae was described. The detector uses a single silicon avalanche photodiode which is sensitive from 0.7 to $1.0 \mu \mathrm{m}$. The detector was optimized in spectra to discriminate between large, moderately hot $\left(400^{\circ} \mathrm{C}\right)$ structures and small, near melting $\left(>800^{\circ} \mathrm{C}\right)$ structures. The detector is still too sensitive to plasma emission and gives a false positive whenever the plasma emission is very high. The detector also is sensitive to plasma disruptions and gives no output for 100 's of milliseconds after one occurs. However, when the plasma is well behaved, which isn't when you really need the detector, it works. Several corrections including moving it away from the vessel and changing the operating spectrum are suggested.

\section{REFERENCES}

[1] Handbook of Chemistry and Physics 60th Edition, CRC Press, 1979, p. E-351. 